\title{
Epidemiological Profile of Congenital Cardiopathy Neonatal Revelation in Tehran
}

Kenari MA*

Department of Nursing, Shahid Beheshti University, Iran

*Corresponding author: Kenari MA, Department of Nursing, Shahid Beheshti University, Iran, Tel: +989120888240, Email: morteza.alibakhshikenari@gmail.com

Citation: Kenari MA (2018) Epidemiological Profile of Congenital Cardiopathy Neonatal Revelation in

Tehran. J Case Rep Stud 6(6): 603. doi: 10.15744/2348-9820.6.603

Received Date: November 9, 2018 Accepted Date: December 29, 2018 Published Date: December 31, 2018

\begin{abstract}
Background: Congenital heart disease is the most common congenital disorder in newborns represents a major cause of perinatal death. The prevalence of these malformations is still unrecognized in Tunisia because of the lack of a national register. The aim of this study was describe the epidemiological and clinical aspects of the heart diseases with neonatal diagnosis in Tunisia.

Methods: A retrospective multicentrc study has been undergone. All the neonates with congenitalheart diseases have been collected in seven neonatal departments in Tunisia, a period of two years (2015 and 2016).

Results: Three hundred cases of congenital heart defects were collected with a prevalence of 3.4 / 1000 live births. These abnormalities are divided into four groups according to pathophysiological mechanisms: Left-right shunt heart disease: (99 cases or 33\%), cyanotic heart disease (129 cases or $43 \%$ ), obstructive heart disease ( 42 cases or $14 \%$ ) and other heart diseases (30 boxes or 10\%). Among all of these heart diseases, $44.7 \%$ had a prenatal diagnosis at a median gestational age of 30 weeks of amenorrhea. $23.1 \%$ of newborns were from consanguineous parents. The mean maternal age was 32 years old. Pre-existing diabetes and gestational diabetes were present in $5.3 \%$ and $9.6 \%$ of cases respectively. The sex ratio was 1.14 . Prematurity was found in $19.4 \%$. low birth weight was denoted in $16.9 \%$ of neonates. $23.3 \%$ of newborns had associated congenital malformations. The average age at diagnosis was 6.69 days. Respiratory distress was the mostcommon symptom (47.7\%). The association with a heart murmur was recorded in $39 \%$ of cases.

Conclusion: Congenital heart diseases are burdened by a significant rate of morbidity and mortality the perinatal period. Their prevalence in our country is still underestimated despite the progress of techniques and means of diagnosis. It is therefore necessary to insist on the need for the creation of a national register of congenital heart diseases listing the various cases reported for the real estimation of the prevalence of these malformations in Tunisia.

Keywords: Congenital Heart Disease; Newborn; Epidemiology; Prevalence; Heart Defects; Congenital

List of abbreviations: AM: Mitral Atresia; APSI: Pulmonary Atresia with Intact Interventricular Septum; APSO: Open Interventricular Septum Pulmonary Atresia; AT: Tricuspid Atresia; CAV: Canal Atrioventricular; CC: Congenital Heart Disease; CIA: interauricular communication; CIV: Interventricular Communication; Hypo LV: Left Ventricular Hypoplasia; InAo: Interruption of the arch aortic; NN: newborn; OR: Single Auricle; RP: pulmonary narrowing; RVPA: Abnormal Pulmonary Venous Return; T4F: Tetralogy of Fallot; TAC: Common arterial trunk; TGV: Transposition of Large Vessels; VDDI: Right Ventricle Double-Out; VU: Single Ventricle
\end{abstract}

\section{Introduction}

Congenital heart disease (CHD) is a cardiac abnormality that occur during the formation of the heart during intrauterine life [1]. They are extremely diverse, ranging from simple benign abnormalities with the growth of the child without major problems until the malformation make the survival of the newborn (NN) impossible. Their impact is estimated between 6 and $9 \%$ live births (NV) [2].

The epidemiology of CC has changed considerably in recent years decades. In fact, the diagnostic conditions for heart disease have transformed over the years through improved techniques non-invasive explorations such as echocardiography and Doppler heart. Similarly, the antenatal diagnosis of CC has greatly developed allowing early and specialized care and contributing, with the advent of interventional cardiac catheterization, with a clear decreased mortality in relation to CC.

In Tunisia, the few studies carried out in this field report a incidence varying from 1 to $1.9 \%$ NV which probably remains underestimated given the large number of early exits of maternal NNs without diagnostic [3]. Conscious of the importance of establishing an inventory of CCs in Tehran, the This work was carried out within the framework of the Study Group on Neonatology (GEN). It proposes to describe the epidemiological and Congenital heart disease clinics emerging in the neonatal period in Tehran. 


\section{Material and methods}

This is a retrospective, multicenter study performed in the context of of the Neonatology Studies Group (GEN). She collected all the NN CC carriers in seven pediatric and neonatal departments in Tunisia (Level II and III neonatal care) over a period of two years from 1st January 2015 to December 31, 2016.

\section{The services that participated in this study are:}

- The neonatology department of the University Hospital Center (CHU) Hédi Chaker of Sfax.

- Neonatology service, Tahar Sfar Hospital in Mahdia.

- Maternity and neonatology center Fattouma Bourguiba de Monastir.

- The neonatal intensive care unit, CHU Farhat Hached, Sousse.

- Pediatric ward CHU IBN JAZZAR, Kairouan.

- Neonatology service of the Military Senior Teaching Hospital of Tehran (HMPIT).

- The neonatology and neonatal resuscitation department of the Maternity and Neonatology of Tehran (CMNT).

We included in our study all NNs with heart disease congenital, diagnosed or not in the antenatal period, confirmed postnatal and having a gestational age between 27 and 42 weeks of late amenorrhea with a birth weight (PN)> 700 grams. The diagnosis of CC was suspected either on the antenatal ultrasound or on clinical criteria and confirmed, in all cases, by cardiac ultrasound postnatal care performed either by a cardiopediatrician or by a cardiologist.

Excluded from the study were all malformations defined as such as inter-auricular communication, persistence of the ductus arteriosus, a diabetic mother's NN cardiomyopathy, a isolated pulmonary artery hypertension, an isolated anomaly of situs or rhythm disorders.

We proceeded to the elaboration of a compilation of the data epidemiological and clinical aspects of congenital heart disease from NN files. The variables thus studied were the original service, the maternal characteristics, the course of pregnancy and childbirth, NN characteristics and diagnostic criteria congenital heart disease (clinical and paraclinical). The treatment of data was generated by SPSS Version 19 software. Analysis and results were expressed on average and as a percentage.

\section{Results}

During the study period, 300 cases of neonatal revelatory identified either a prevalence of $3.4 \%$ NV. The distribution of patients according to service of origin is shown in Table I. In $83 \%$ of cases, patients are born in-born. In-utero transfers were noted in 25 cases. CCs have have been classified according to the physiological mechanism in four groups:

\begin{tabular}{|c|c|c|}
\hline Original service & Effective & Percentage (\%) \\
\hline CMMT & 62 & 20.7 \\
\hline Sfax Teaching Hospital & 48 & 16 \\
\hline CHU Monastir & 50 & 16.7 \\
\hline CHU Mahdia & 24 & 8 \\
\hline CHU Sousse & 78 & 26 \\
\hline HMPIT & 20 & 6.6 \\
\hline CHU Kairouan & 18 & 6 \\
\hline Total & 300 & 100 \\
\hline
\end{tabular}

Table 1: Distribution of Congenital Heart Disease by Source of Service CHU: University Hospital Center, CNMT: Tunis Maternity and Neonatology Center, HMPIT: Hospital Senior Military Training of Tehran.

1- left-right shunt heart disease was observed in 99 patients or 33\% of the total cases. Interventricular communication (IVC) has represented a rate of $84.9 \%$ of the cases in this group. The atrio-ventricular canal (CAV) was present in $15 \mathrm{NN}$ or a rate of $15.1 \%$ of shunt heart disease left right.

2- Cyanogenic heart diseases were noted in 129 patients, ie $43 \%$ of total cases. Transposition of large vessels (TGV) has been heart disease dominant cyanogen with a rate of $11.3 \%$. She was followed by the ventricle unique (VU) with a rate of $9 \%$. The tetralogy of Fallot (T4F) and atresia pulmonary septum intact (APSI) accounted for $6.3 \%$ and $4.7 \%$, respectively cases.

3- Obstructive heart disease was present in 42 patients, ie 14\% of the total CCs. Aortic coarctation (CoAo) accounted for 31\% of cases group followed by hypoplasia of the left ventricle (Hypo VG) and the interruption of the arch (InAo) with a rate of $23.8 \%$ for each. The Pulmonary narrowing (PR) was less important with a rate of $21.4 \%$.

4- Other congenital heart defects were observed in 30 patients that is $10 \%$ of the cases. Table II summarizes the distribution of CC by class physiological. With regard to family characteristics, the median maternal age was 32 years and $29.6 \%$ of parturients were 
over 35 years old. A parental consanguinity was present in $23.1 \%$ of cases. An antecedent of CC in the siblings was noted in $2.7 \%$ of cases and in the mother in 3\% of cases. Maternal pathologies were dominated by diabetes, ie $5.3 \%$ of women in labor. The main gravid diseases have been diabetes pregnancy and toxemia with a respective rate of 9.6 and $3.3 \%$.

\begin{tabular}{|c|c|c|c|}
\hline Type of CC & & Number & Percentage (\%) \\
\hline Shunt heart disease & CIV & 84 & 28 \\
left right & CAV & 15 & 5 \\
\hline heart Disease cyanogenic & TGV & 34 & 19 \\
& T4F & 6.3 & 11.3 \\
& TAC & 6 & 2 \\
& APSO & 6 & 2 \\
& APSI & 14 & 4.7 \\
& RVPA & 4 & 1.3 \\
& Seen & 27 & 9 \\
& OR & 3 & 1 \\
& AT & 8 & 2.7 \\
& AM & 1 & 0.3 \\
& Ebstein & 5 & 1.7 \\
& VDDI & 2 & 0.7 \\
\hline Heart disease by obstacle & InAo & 10 & 3.3 \\
& CoAo & 13 & 4.4 \\
& hypo & 10 & 3.3 \\
& VG & 9 & 3 \\
\hline RP & & \\
\hline Other heart diseases & & 30 & 10 \\
\hline Total & & 300 & 100 \\
\hline
\end{tabular}

Table 2: Distribution of different types of congenital heart disease

CIV: interventricular communication, CAV: atrioventricular canal, TVG: transposition of large vessels, T4F: tetralogy of Fallot, TAC: common arterial trunk, APSO: open septum pulmonary atresia, APSI: intact septal pulmonary atresia, RVPA: abnormal pulmonary venous return, UL: single ventricle, OR: single atria, AT: tricuspid atresia, AM: mitral atresia, Ebstein: Ebstein's disease, VDDI: ventricle double-ended right, InAo: Interruption of the arch of the aorta, CoAo: coarctation of the aorta, Hypo VG: hypoplasia left ventricle, RP: pulmonary narrowing.

\section{Pregnancy follow-up in line with the recommendations was noted in}

\begin{tabular}{|c|c|c|}
\hline Type of heart disease & Number & Median GA of discovery (HER) \\
\hline CIV & $20 / 84$ & $\mathbf{2 8}$ \\
\hline CAV & $8 / 15$ & $\mathbf{3 2}$ \\
\hline TGV & $7 / 34$ & $\mathbf{2 7 . 6}$ \\
\hline T4F & $4 / 19$ & $\mathbf{2 9}$ \\
\hline APSI & $2 / 14$ & $\mathbf{2 2}$ \\
\hline APSO & $1 / 6$ & $\mathbf{3 5}$ \\
\hline Ebstein & $1 / 5$ & $\mathbf{3 5}$ \\
\hline RVPA & $1 / 4$ & $\mathbf{N P}$ \\
\hline VDDI & $1 / 2$ & $\mathbf{3 4}$ \\
\hline VU & $16 / 27$ & $\mathbf{2 8}$ \\
\hline OR & $1 / 3$ & $\mathbf{2 6}$ \\
\hline TAC & $2 / 6$ & $\mathbf{2 8}$ \\
\hline AT & $1 / 8$ & $\mathbf{3 6}$ \\
\hline AM & $1 / 1$ & 36 \\
\hline CoAo & $1 / 13$ & 27 \\
\hline InAo & $1 / 10$ & NP \\
\hline Hypo VG & $5 / 10$ & 29 \\
\hline RP & $1 / 9$ & 29 \\
\hline Other heart diseases & $10 / 30$ & 30 \\
\hline
\end{tabular}

Table 3: Distribution of different types of congenital heart disease diagnosed in antenatal

CIV: interventricular communication, CAV: atrioventricular canal, TVG: transposition of large vessels, T4F: tetralogy of Fallot, TAC: common arterial trunk, APSO: open septum pulmonary atresia, APSI: intact septal pulmonary atresia, RVPA: abnormal pulmonary venous return, UL: single ventricle, OR: single atria, AT: tricuspid atresia, AM: mitral atresia, Ebstein: Ebstein's disease, VDDI: ventricle double-ended right, InAo: Interruption of the arch of the aorta, CoAo: coarctation of the aorta, Hypo VG: hypoplasia left ventricle, RP: pulmonary narrowing. 
$58.8 \%$ of cases. Among 188 prenatal ultrasounds performed, the diagnosis antenatal CC was suspected in 84 cases, a rate of $44.7 \%$ at an age median gestational 30 weeks of amenorrhea. The sensitivity of Morphological ultrasound has been variable depending on the type of cardiopathy as well as the operator (Table 3). It has been better for heart disease with major impairment of cardiac architecture and for ultrasound case performed by a radiologist.

The sex ratio in our study was 1.14 . The percentage of premature birth in NN carriers was $19.4 \%$ of cases. A delay of Intrauterine growth was noted in $16.9 \%$ of newborns. A score Apgar $\leq 7$ to 5 minutes of life was recorded in $8.5 \%$ of cases.

The association between cardiopathy and other congenital malformations has observed in 70 cases, a rate of $23.3 \%$. Frequency of aberrations chromosomes was $12 \%$. It was trisomy 21 in $8.3 \%$ of cases. The most common heart disease in Down syndrome 21 was the CAV with a $44 \%$ of cases. The different syndromes diagnosed summarized in Table 4.

\begin{tabular}{|c|c|c|c|}
\hline Syndromes & Number & Percentage (\%) & Types of CC \\
\hline \multirow[t]{8}{*}{ T21 } & 25 & 25 & $10 \mathrm{CAV}$ \\
\hline & & & $8 \mathrm{CIV}$ \\
\hline & & & $2 \mathrm{CIV}+\mathrm{CIA}$ \\
\hline & & & $1 \mathrm{~T} 4 \mathrm{~F}$ \\
\hline & & & $1 \mathrm{~T} 4 \mathrm{~F}+\mathrm{CAV}$ \\
\hline & & & $1 \mathrm{VDDI}$ \\
\hline & & & 1 Hypo VG \\
\hline & & & $1 \mathrm{InAo}$ \\
\hline T18 & 1 & 0.3 & $1 \mathrm{CIV}$ \\
\hline \multirow[t]{2}{*}{ VACTERL Association } & \multirow[t]{2}{*}{3} & \multirow[t]{2}{*}{1} & $2 \mathrm{CIV}$ \\
\hline & & & $1 \mathrm{VU}$ \\
\hline Sd of Goldenhar & 1 & 0.3 & $1 \mathrm{TGV}$ \\
\hline \multirow[t]{3}{*}{ Sd of Digeorge } & \multirow[t]{3}{*}{4} & \multirow[t]{3}{*}{1,3} & $2 \mathrm{~T} 4 \mathrm{~F}$ \\
\hline & & & $1 \mathrm{APSO}$ \\
\hline & & & $1 \mathrm{InAo}$ \\
\hline Sd of Noonan 10.31 APSO & 1 & 0.3 & 1 APSO \\
\hline heterotaxia viscèroatriale & 1 & 0.3 & $1 \mathrm{CAV}$ \\
\hline Telomic deletion of chro 7 & 1 & 0.3 & $1 \mathrm{CIV}$ \\
\hline
\end{tabular}

Table 4: Syndromic syndromes diagnosed in newborns

T21: trisomy 21, T18: trisomy 18, Sd: syndrome, Telomic deletion of chro 7: Telomic deletion of chromosome 7, CAV: atrioventricular canal, CIV: interventricular communication, CIA: communication interauricular, T4F: tetralogy of Fallot, VDDI: right ventricle with double outlet, Hypo VG: hypoplasia of left ventricle, InAo: interruption of the arch of the aorta, VU: single ventricle, TGV: transposition of large vessels, APSO: open septal pulmonary atresia.

Congenital heart disease was symptomatic in $73.3 \%$ of patients with case. Table 5 presents the different clinical symptoms. The median age of discovery of heart disease was 3.8 days with extremes of 1 and 60 days. The chest X-ray was normal in $47.3 \%$ of cases. She showed a cardiomegaly in $34.3 \%$ of cases. The electrocardiogram was performed in $50.3 \%$ of the cases. The most common anomaly was noted rhythm disturbances in 3\% of cases. Cardiac CT angiography and cardiac catheterization diagnosis were performed respectively in 27 and 2 cases.

\begin{tabular}{|c|c|c|}
\hline Clinical Signs & Number of Cases & Percentage (\%) \\
\hline NRNR & 143 & 47.7 \\
\hline Heart murmur & 117 & 39 \\
\hline Central cyanosis & 110 & 36.7 \\
\hline IC & 28 & 9.3 \\
\hline Peripheral pulse abnormality & 10 & 3,3 \\
\hline Rhythm disorders & 2 & 0.7 \\
\hline
\end{tabular}

Table 5: Distribution of Congenital Heart Disease by Symptomatology clinical DRNN: neonatal respiratory distress, IC: heart failure.

\section{Discussion}

In our series, the overall prevalence of CC, of all types, has been of $3.4 \%$ NV. This rate is significantly lower than that reported in the literature. According to a meta-analysis by Van Der Linde et al including 114 global epidemiological studies, the prevalence of 
$\mathrm{CC}$ is variable from one population to another [4]. The estimate of 8 per $1000 \mathrm{NV}$ is currently the more accepted [5]. According to this meta-analysis, the lowest rate is recorded in Africa $(1.9 \% \mathrm{NV})$. This is explained by ethnic factors and genetic. In Tunisia, the small number of studies dealing with this subject reports a prevalence of 1 to $2.7 \%$ NV (see Table 6). This great disparity in the results can be explained, in part, by the criteria of inclusion that vary from one study to another. In ours, we have excluded minor heart diseases whose frequency is not negligible. In other part, these noticeable gaps can find an explanation in the change diagnostic means because of technical progress.

\begin{tabular}{|c|c|c|c|}
\hline Period & Location & Study Reference & Prevalence (\%o NV) \\
\hline $1994-2003$ & Pediatric Department of Bizerte & {$[6]$} & 2.5 \\
\hline 2009 & Neonatology Department of Sousse & {$[3]$} & 1.1 \\
\hline $2014-15$ & Neonatology Department of Sousse & {$[7]$} & 2.7 \\
\hline \multicolumn{2}{|c|}{ Table 6: Global Prevalence of Congenital Heart Disease in Tehran } \\
\hline
\end{tabular}

The distribution of the different types of CC is also variable according to the series. Our results were broadly consistent with the literature in out of a few exceptions that have been easily explained (see table 7):

\begin{tabular}{|c|c|c|}
\hline Type of CC & Meta-analysis [4] (\%) & Our study (\%) \\
\hline CIV & 34 & 28 \\
\hline CAV & - & 5 \\
\hline TGV & 5 & 11.3 \\
\hline T4F & 5 & 6.3 \\
\hline VU & - & 9 \\
\hline CoAo & 5 & 4.3 \\
\hline RP & 8 & 3 \\
\hline
\end{tabular}

Table 7: Comparison of the distribution of some heart diseases congenital with world series

Compared to the global series, we noted a higher rate TGV (11.3\% vs. 5\%) and a lower rate of CIV (28\% 34\%) and PR (3\% vs. $8 \%$ ). This could have an explanation in the meta-analysis previously cited [4]. Indeed, among the differences significant geographical areas ( $\mathrm{p}<0.001$ ), Africa has a higher rate TGV and a lower rate of CIV, RP, CoAo and compared to Europe, North America, South America and Oceania (see Figure 1).

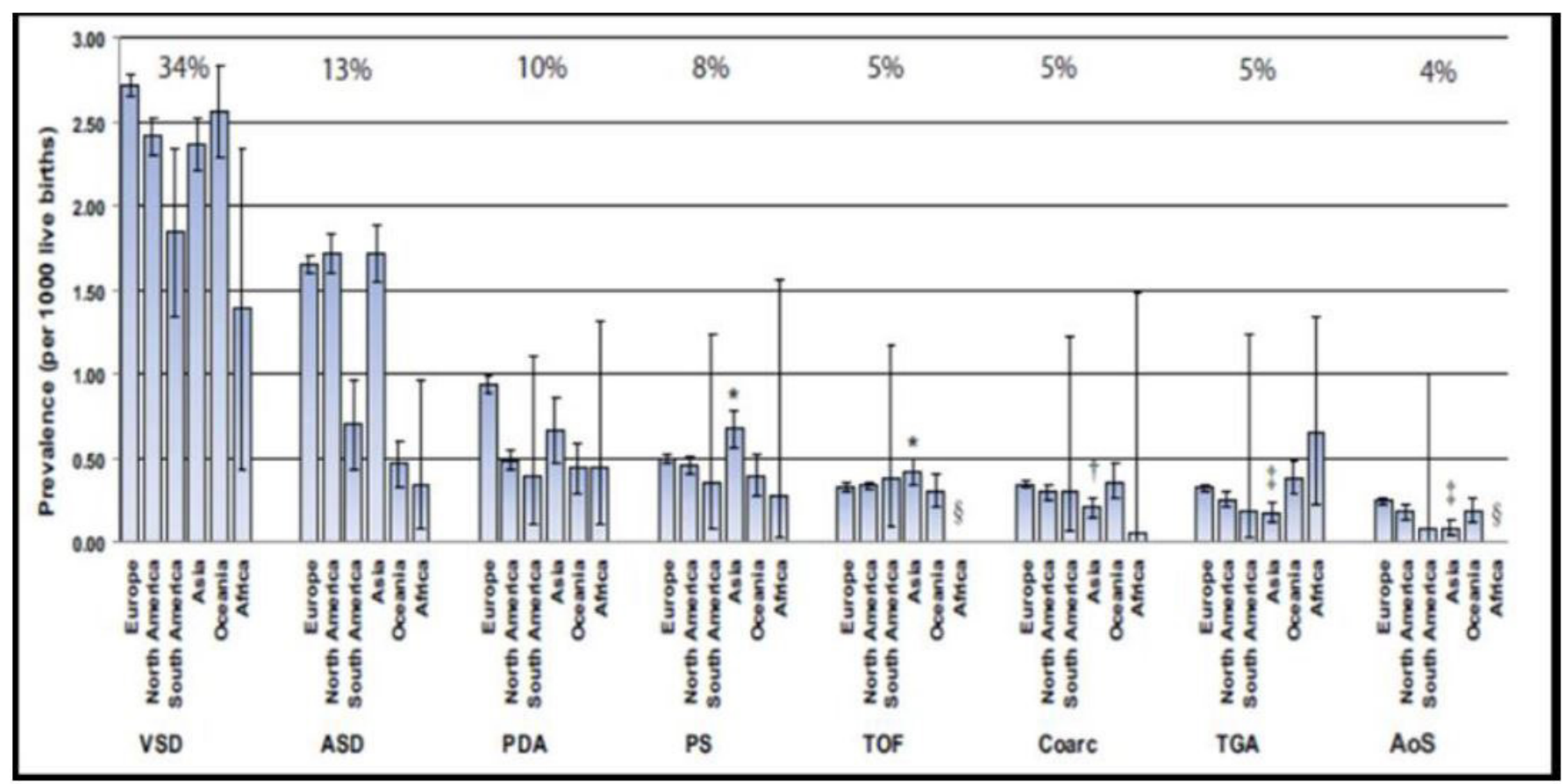

Figure 1: Global Distribution of Major Types of Heart Disease [4]

The UL rate was significantly higher than that reported in the literature [8]. The insufficiency of prenatal diagnosis that leads typically in this type of CC at an IMG could explain this difference.

\section{Maternal characteristics}

The frequency of CC is higher in communities with greater consanguinity. As an indication, in India where the prevalence of CC is 
high $(9.3 \% \mathrm{NV})$, about $43 \%$ of subjects with DC have consanguinity parental [4]. Some studies also note a high prevalence of CC in NNs from mothers $\geq 35$ years of age $[9,10]$. This could to be explained by the increased risk of genetic mutations as the maternal age increases. In addition, the role of pre-existing diabetes and gestational diabetes in the increased risk of DC is well determined in the literature [11]. It increases the risk of all types of malformations and heart disease in particular [12,13]. The risk of CC seems to be closely correlated with the quality of the glycemic balance during conception and embryogenesis. Strict control of blood glucose reduces significantly this risk.

In our study, the risk of CC recurrence among siblings was $2.7 \%$ and $3 \%$ in the case of maternal impairment. However, we found that the type of heart disease patients carried was different from their mothers or of their seniors reached. These results have joined those of the literature that if a previous child is injured, the risk of recurrence of CC is 2 at $3 \%$. This rate can reach 5 to $6 \%$ in case of attack of one of the parents and $10 \%$ if two or more children are affected varies by type and the severity of the CC [14,15]. It is particularly important for isomerism, left obstructive heart disease and especially when the malformation fits into a well-defined genetic framework [15-17]. On the other hand, the degree of concordance is variable from one heart disease to another. So the type of CC in case of recurrence may be different from that of the index case [18].

\section{Prenatal screening}

In our study, the antenatal screening rate was $44.7 \%$. According to this rate continues to increase thanks to the considerable growth of fetal morphological ultrasound. It presents a great disparity according to countries and regions and reaches $71 \%$ in some countries, such as the Upper Normandy [19,20]. Regarding the type of CC detected in our series, the screening rate was higher in the case of UL, CAV, Hypo VG and VDDI. It was weak for the CIV, the T4F and the TGV. It is the same in the literature where the screening rate is the best for DC without repair anatomical possible. It can reach, for example, $90 \%$ in case of LV hypo.

This is explained by a very altered cardiac architecture and easily locatable. It is steadily increasing for simple CCs such as the CIV and is, on the other hand, relatively lower for the TGV (70\%) [21]. However, T4F, is considered a malformation whose screening is difficult requiring training and regular training $[20,22]$.

\section{Characteristics of newborns}

In our study, a slight male predominance was noted (sexratio =1.14). In this respect, the studies are discordant. The breakdown by sex CC is variable depending on the series. It also varies according to the type of CC [23]. With regard to intrauterine growth retardation, there is evidence significant association with CC [24]. In the series of Martinez et al, Ce rate is 22\% [25]. Although the reasons for this association remain unclear, some potential explanations are proposed in case of VU. They suggest that poor fetal growth is a response to bad fetal heart circulation [26].

Some of these CCs are associated with chromosomal abnormalities. He This is mainly trisomy 21, trisomy 18 , trisomy 13 , triple $\mathrm{X}$ and $45 \mathrm{XO}[27,28]$. Among these aberrations, the T21 is the most widespread. She is associated more than $50 \%$ of cases with a CAV [29]. The T18 comes in second and has cardiopathy in more than 75\% of cases, often of type CIV [30]. The association with gene abnormalities is rarer. According to the study of Robert GE et al, 20\% of fetuses with conotruncal heart disease are $22 \mathrm{q} 11$ microdeletion carriers with different prevalence depending on the type of CC: InAo (45\%), T4F with no pulmonary valve (37.5\%), TAC (31\%), AP with CIV (18\%), T4F (14\%) and complex TGV (12\%) [31].

\section{Diagnosis of congenital heart disease}

It is essential to diagnose DC in time. Any delay in diagnosis has a serious risk of morbidity, mortality and disability [32]. Clinical examination allows diagnosis only in 50 to $75 \%$ of cases since some cardiopathies remain asymptomatic for a long time [33]. According to a Swedish study, 4.6 deaths out of $100,000 \mathrm{NV}$ are attributed to CC not detected despite the fact that $52 \%$ of them are considered to be serious and required resuscitation [34].

The result of this study shows that the pulse rate response of the participants was significant when compared to their mean pulse rate at rest before the exercise. This is in line with the study by Nishime et al., (2000) who reported a significant difference in pulse rate of hemiplegic stroke survivors after early treadmill exercise irrespective of gender, the rise in pulse rate is due to a central withdrawal of parasympathetic arteriole during exercise. However, a comparison of the means of pulse rate between male and female participants indicated no significant difference; which was in line with the study by Zdenek et al., (2010) who discovered no significant difference on comparison between genders. However, an article by Mackay-Lyons et al, (2002) briefly mentioned gender difference in their data set but they had a smaller sample size and an unequal distribution of male (22) and females (7) in their study. They reported a significant difference with male participants having higher pulse rate values.

The comparison of the mean systolic blood pressure response of the participants after Treadmill walking exercise and the mean systolic blood pressure response of the participants at rest shows significant difference among male and female participants. This is consistent with the study by Kannel et al., (1991) who reported an increase in systolic blood pressure which is statistically significant. The increase in systolic blood pressure during exercise increase the cardiac output brought about by increase in stroke volume and pulse rate, which exerts higher pressure on the blood vessels during the systolic phase of the cardiac circle (McAdle 
et al, 2000). This was not in line to a study by Moreira et al., (1999) which shows that blood pressure response was greater in their study with treadmill exercise but changes were not significant. Also, comparison of the means of systolic blood pressure between male and female participants indicated a significant difference with female participants having higher values, this is in agreement with a report by Kusuma et al.,(2002) who observed a significant difference in blood pressure response between gender, Another research by Gardner and Poehlman, (2001) reported a positive and significant difference in blood pressure between male and female participants with male participants having higher values for blood pressure.

Moreover, the presence of a heart murmur is frequent in period neonatal [33]. It allows suspecting a CC and offers the possibility of a early detection. However, it can be physiological [35]. According to one study conducted in the United States, 29.5\% of nonsyndromic diagnosed after more than three days of birth. In analysis multivariate, the study shows that the free detection interval varies significantly depending on the type of CC. NN with intracardiac defect are more likely to have an asymptomatic transitional period longer misleading [36]. This period depends on variations hemodynamics namely the closure of the arterial duct and the shunts that can stay longer balanced by vascular resistance raised at birth [37]. Two-dimensional echocardiography with pulsed or doppler Doppler color shows a very high sensitivity and specificity. She represents the complementary investigation of choice in the diagnosis of a CC [38].

Doppler mode is used in the non hemodynamic evaluation invasive pressure gradients of the right ventricle and pulmonary artery and through the heart valves [39]. Nevertheless, this technique requires significant investment in time and staff and a high cost not justifying its use in the neonatal screening of CC [40]. The electrocardiogram, although frequently used, is an examination of non-sensitive and nonspecific CC testing unless arrhythmia is present [41]. A normal ECG electrocardiogram does not exclude a CC hemodynamic repercussions. In contrast, arrhythmias are usual manifestations of CC [38].

Cardiac CT angiography has been increasingly neglected since the advent of the multi-scan scanner. This technique (rapid acquisition and limitation of irradiation) represents a real progress in the exploration of CCs because it provides a non-invasive, high quality three-dimensional imaging [42]. Similarly, cardiac catheterization for diagnostic purposes mainly reserved for hemodynamic evaluation is less and less used because the development of echocardiography and other non-invasive techniques [43].

Strengths and weaknesses Our study was the first multicentre study focusing on neonatal revelation in Tunisia. It included the main services of neonatology. However, it did include some limitations that could influences relatively the interpretation of the results. Indeed : We did not include other services that support NNs carriers (general pediatric, cardiopediatric, public sector ...) which reduces the size and diversity of the study population. We have not included, also, certain heart diseases defined as children whose prevalence is not negligible.

In addition, data collection was limited by the retrospective nature of the study. As a result, some information was missing and could make our less relevant and underestimated results. On the other hand, some patients transferred to another health facility (abroad, to services cardiopediatrics). Thus, patient follow-up was limited in some cases by because of difficulties in contact and follow-up.

\section{Conclusion}

CC are the most common congenital anomalies. These malformations are burdened with significant morbidity and a rate of significant mortality in the perinatal period. Their prevalence in our country is still underestimated despite the progress of techniques and means diagnosis. It is important to stress the need for the creation of a register national report listing the different cases reported for the actual estimate of the prevalence of CC in Tunisia.

\section{References}

1. Siu SC, Sermer M, Colman JM (2001) Prospective multicenter study of pregnancy outcomes in women with heart disease. Circulation 104: 515-21.

2. Hoffmann JI, Kaplan S (2002) The incidence of congenital heart disease. J Am Coll Cardiol 39: 1890-900.

3. Methlouthi J, Mahdhaoui N, Mougou S, Ghannem S, Bellaleh M, et al. (2015) Epidemiology of Congenital heart diseases diagnosed in the neonatal period. Cardiol Tunis 2: 102-7.

4. Van der Linde D, Konings EE, MA Slager, Witsenburg M, Helbing WA, et al. (2011) Birth prevalence of congenital heart disease worldwide: a systematic review and meta-Analysis. J Am Coll Cardiol. 58: 2241-7.

5. Bernier PL, Stefanescu A, Samoukovic G, Chervenkov CI (2010) The challenge of congenital heart disease worldwide: epidemiologic and demographic facts. Semin Thorac Cardiovascular Surg Pediatr Card Surg Annu. 13: 26-34.

6. Hammami O, Ben Salem K, Zied B, Chebbi Y, Aoun S, et al. (2007) Epidemiological profile and Clinic of Congenital Heart Disease in Children at Bizerte Hospital. Tunis Med 85: 829-33.

7. Methlouthi J, Mahdhaoui N, Bellaleh M, Guith A, Zouari D, et al. (2016) Study of the incidence of Congenital heart diseases in the newborn after introduction of transcutaneous saturation in the screening protocol. Tunis Med 94: 231-4.

8. Steinberger EK, Ferencz C, Loffredo CA (2002) Infants with single ventricle: a population-based epidemiological study. Teratology 65 : 106-15.

9. Best KE, Rankin J (2016) Is advanced maternal age at risk factor for congenital heart disease? Birth Defects Res A Clin Mol Teratol 106: 461-7.

10. Hunt PA, Hassold TJ (2008). Human female meiosis: what makes a good egg go bad? Trends Genet 24: 86-93.

11. Ferencz C, Rubin JD, Mc Carter RJ, Clark EB (1990) Maternal diabetes and cardiovascular malformations : predominance of double outlet right ventricle and truncus arteriosus. Teratology 41: 319-26. 
12. Jenkins KJ, Correa A, Feinstein JA, Botto L, Britt AE, et al. (2007) Non inherited risk factors and congenital cardiovascular defects: Current knowledge of a scientific statement from the American Heart Association Council on Cardiovascular Disease in the Young. Circulation 115: 2995-3014.

13. Chih-Ping C (2005) Congenital malformations associated with maternal diabetes. Taiwan J Obstet Gynecol 44: 1-7.

14. Hoffman JI (1995) Incidence of congenital heart disease II. Prenatal incidence. Pediatr Cardiol. 16: 155-65.

15. Jouannic JM (2010) Fetal cardiac abnormalities: prenatal diagnosis and perinatal management. Encycl Med Chir. (Elsevier Masson, Paris).

16. Viot G (2002) Congenital heart disease: what risk for siblings? J Pediatr Intensive Care 15: 259-64.

17. Davison BC (1997) Concordance and discordance of congenital heart disease in 20 families. J Med Broom. 4: 245-50.

18. Gill HK, Splitt M, Simpson JM (2003) Pattern of recurrence of congenital heart disease. J Am Coll Cardiol 4: 923-9.

19. Gascard-Battisti C, Dubois-Lebbe C, Chatelet-Cheront C, Ferrant L, Sales A, et al. (2006) Antenatal screening for congenital heart defects: a 20 -year retrospective study. J Gynecol Obstet Biol Reprod 35: 472-6.

20. Blaysat G, David N, Durand I (2001) Antenatal diagnosis of congenital heart disease in Upper Normandy Normandy: retrospective study from 1995 to 1998. Rev Int Pediatrics 23: 9-12.

21. Khoshnood B, Vigan C, Vodovar V, Goujard J, Man A, et al. (2005) Trends in prenatal diagnosis, pregnancy termination, and perinatal mortality of newborns with congenital heart disease in France, 1983-2000: a population-based evaluation. Pediatrics 115: 95-101.

22. Allan L (2000) Antenatal diagnosis of heart disease. Heart 83: 367.

23. Aubry P, Demian H (2016) Gender differences in congenital heart disease. Ann Cardiol Angeiol. 65: 440-5.

24. Petrossian RA, Kuehl KS, Loffredo CA (2015) Relationship of birth weight with congenital cardiovascular malformations in a population-based study. Cardiol Young. 25: 1086-92.

25. Martníez OP, Ibarra CR, Alzina AV (2005) Incidence of Congenital Heart Disease in Navarra, Spain 1989- 1998. Rev Esp Cardiol 58: 1428-34.

26. Hannan RL, Ybarra MA, Ojito JW, Alonso FA, Rossi AF, et al. (2006) Neonatal complex single ventricle palliation using antegrade cerebral perfusion. Ann Thorac Surg 82: 1278-84.

27. Ekure EN, Animashaun A, Bastos M, Ezeaka VC (2009) Congenital heart diseases associated with identified syndromes and other extra-cardiac congenital malformations in children in Lagos. West Afr J Med 28: 33-7.

28. Trevisan P, Zen TD, Rosa RF, Silva JN, Koshiyama DB, et al. (2013) chromosomal abnormalities in patients with congenital heart disease. Arq Bram Cardiol 9: $17-22$.

29. Stos B, Dembour G, Ovaert C, Barrea C, Arape A, et al. (2004) Benefits and risks of heart surgery in trisomy 21. Arch pediatr 11: 1197-201.

30. Sepulveda W, Wong AE, Dezerega V (2010) First-trimester sonographic findings in trisomy 18: a review

of 53 cases. Prenat Diagn 30: 256-9

31. Robert GE, Francannet C, Bozio A, Bouvagnet P (2004) Epidemiology, etiology and genetics of Congenital heart disease, Encycl Med Chir. (Elsevier Masson, Paris), Cardiology-Angeology, 1, 21.

32. Brown KL, Ridout DA, Hoskote A, Verhulst L, Ricci M, et al. (2006) Delayed diagnosis of congenital heart disease worsens preoperative condition and outcome of surgery in neonates. Heart 92: 1298-302.

33. Arlettaz R, Bauschatz AS, Mönkhoff M, Essers B, Bauersfeld U (2005) The contribution of pulse oximetry to the early detection of congenital heart disease in newborn. Eur J Pediatr 165: 94-8.

34. De-Wahl Granelli A, Wennergren M, Sandberg K, Mellander M, Bejlum C, et al. (2009) Impact of pulse oximetry screening on the detection of duct-dependent congenital heart disease prospective screening study in 39,821 newborns. BMJ 338: 3037.

35. Lardhi AA (2010) Prevalence and clinical significance of heart murmurs detected in neonatal routine examination. J Saudi Heart Assoc 22: 25-7.

36. Peterson C, Wings E, Riehle-Colarusso T, Oster ME, Olney RS, et al. (2014) Late Detection of Critical Congenital Heart Disease Among US InfantsEstimation of the Potential Impact of Proposed Universal Screening Using Pulse Oximetry. JAMA Pediatr168 : 361-70.

37. Marino BS, Bird GL, Wernovsky G (2001) Diagnosis and management of the newborn with suspected congenital heart disease. Clin Perinatol. 28: 91-133.

38. O'Connor M, Daniel Mc N, Brady WJ (2008) The pediatric electrocardiogram Part III: Congenital heart disease and other cardiac syndromes . Am J Emerg Med $26: 497-503$

39. Moceri P, Dimopoulos K, Liodakis E, Germanakis I, Kempny A, et al. (2012) echocardiographic predictors of outcome in Eisenmenger syndrome. Circulation 126: 1461-8

40. Singh Y (2017) Echocardiographic Evaluation of Hemodynamics in Neonates and Children. Front Pediatr. 5: 201.

41. Balaji S, Harris L. Atrial arrhythmias in congenital heart disease. Cardiol Clin 20: 459-68.

42. Paul JF, Lambert V (2009) Computed tomography scan of congenital heart disease. Encycl Med Chir. (Elsevier Masson, Paris).

43. Di Bernardo S, Mivelaz Y, Meijboom EJ, Sekarski N (2005) Treatment of Congenital Heart Disease by interventional catheterization. Rev Med Switzerland 2049: 55-9. 


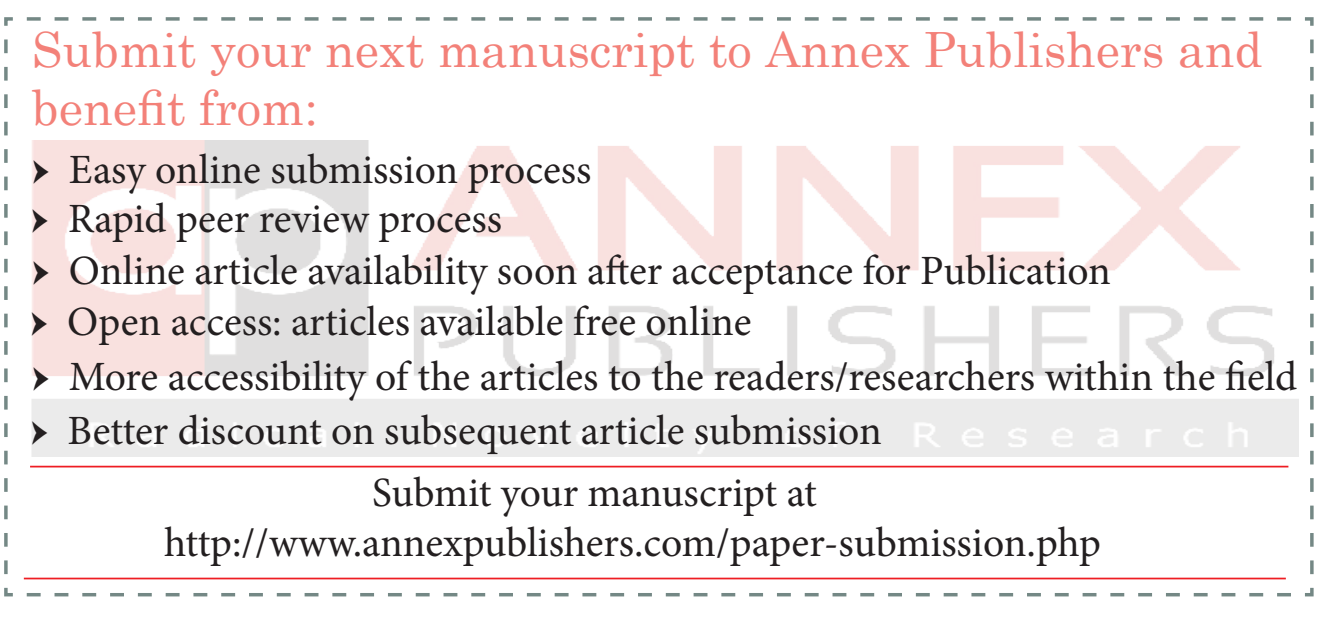

